\title{
Putting theory to practice: Teaching the 5E learning cycle through immersive experiences for pre-service teachers
}

\author{
Mahsa Kazempour ${ }^{1}$, Aidin Amirshokoohi ${ }^{2 *}$ and Katrin Blamey ${ }^{3}$ \\ ${ }^{1}$ Early Childhood \& Elementary Education, Penn State Berks, Reading, USA \\ 2,3* Early Childhood \& Elementary Education, DeSales University, Center Valley, USA \\ For correspondence: muk30@psu.edu
}

\begin{abstract}
:
Studies focusing on pre-service teachers have shown that the inclusion of the learning cycle model in a methods course result in improvement in understanding of and attitude toward the learning cycle model of inquiry. However, preservice teachers' understanding and beliefs about the learning cycle model may remain varied and inaccurate and their implementation may be inhibited due to their beliefs about teaching and learning and roles as teachers. In this article, we will discuss our extended 5E learning cycle model introduction approach consisting of active engagement and immersion of preservice teacher in the process of learning about the $5 \mathrm{E}$ model.
\end{abstract}

Keywords: science inquiry; learning cycle; elementary pre-service teachers, science education

\section{Introduction}

Elementary preservice teachers often have had negative prior experiences with science and hold various beliefs not aligned with science education reform (Appleton, 2006; Kazempour \& Sadler, 2015; Bleicher, 2009). This population typically relate their attitude and lack of confidence in learning and teaching science to their own prior experiences which they normally report as being limited or consisting primarily of teacher directed discussions, text-based readings, and some sporadic activities (Kazempour, 2013, 2014; Kazempour \& Sadler, 2015; Tosun, 2000). Most report not participating in any authentic science investigations. At the same time, national reform movements have continually touted inquiry-based and authentic student learning, particularly in the earlier grades, in order to allow children to develop scientific literacy and scientific inquiry skills. The challenge facing science educators is to provide pre-service teachers with numerous opportunities for inquiry-based learning experiences in order to gain a better understanding of the process through direct first-hand experience.

The learning cycle model, particularly the popular and widely used 5E version (Bybee, 1997), captures the essence of inquiry-based instructional approach. The core of the model focuses on the constructivist-based notion of allowing students to explore the concepts through first-hand experiences before the formal introduction of concepts via the text and/or the teacher. In this way, the learning cycle addresses the limitations of both the teacher-directed model of direct instruction as well as the 'activitymania' approach (Moscovici, 1998) which consists of incorporating sporadic and disjointed activities void of any meaningful purpose and conceptual connection. The learning cycle model also emphasizes the importance of initiating the learning experience by engaging the students and piquing their curiosity, ensuring that students have opportunities to apply their newly gained understanding of concepts, and evaluating student understanding throughout the cycle through diagnostic, formative, and summative assessments. 
Over the past three decades, studies concerning the learning cycle have suggested positive outcomes including augmented student attitudes toward science and science learning, enhanced science achievement, and improvement in concept retention and reasoning skills (Abraham \& Renner, 1989; Beeth \& Hewson, 1999, McComas, 1992). Similarly, studies focusing on pre-service teachers have shown that the inclusion of the learning cycle model in a methods course resulted in improvement in their understanding of and attitude toward the learning cycle model of inquiry-based instruction and learning (Hanuscin \& Lee, 2008). However, other studies have indicated that, despite training and instruction, pre-service teachers' understanding and beliefs about the learning cycle model may remain varied and inaccurate (e.g. Settlage, 2000) and their implementation of the learning cycle in their teaching may be abated or altogether inhibited due to their beliefs about teaching and learning and their roles as teachers (Glasson \& Lalik, 1993). The learning cycle model often appears counterintuitive for pre-service teachers since it contradicts their own K-12 science experiences. Such experiences have been limited to either the 'activitimania' approach of only engaging in random activities or teacher directed science instruction consisting of teacher lecture and class discussions whereby the concepts are fully described by the teacher with occasional confirmation activities. Hence, pre-service teachers may continue to struggle with the idea of incorporating repeated explorations for understanding a particular concept (Hanuscin \& Lee, 2008) or not introducing concepts prior to student exploration.

As with any other pedagogical concept, repeated exposure and multiple modeling, reflection, discussion, and practice are necessary for preservice teachers to understand and effectively utilize the learning cycle (Hanuscin \& Lee, 2008; Kazempour \& Sadler, 2015). The multiple immersive experiences with the learning cycle are critical in allowing preservice teachers to have a better understanding of the process from a learner's perspective and challenge their long-held beliefs about learning. It is equally important for them to be provided opportunities to think as teachers and apply their understanding of the learning cycle model in order to plan effective inquiry-based lessons following this approach..

\section{Context}

We (first two authors) each began utilizing the 5E learning cycle model in the earliest methods courses we taught. Our goal was not only to teach about inquiry-based learning, particularly the 5E learning cycle model, but also utilizing the approach so that students would be able to experience it first-hand. Our own teacher preparation courses had often only included discussions about constructivism, inquiry-based learning, and other science education ideas without allowing us to experience them and fully understand what each would entail. Even though we were both intrigued and extremely enthusiastic about implementing such ideas in our teaching, we had often found ourselves trying to put theory into practice without having been exposed to any practical and tangible examples of what such ideas would actually look like in the classroom. Therefore, in better preparing the elementary preservice teachers in our methods courses, we wanted to steer away from simply presenting these ideas and instead allow our students to actually experience them first hand before being introduced to the ideas. Over the years, we have increased the extent of the learning cycle implementation in our courses to ensure that we do not limit addressing the topic of the learning cycle to only a designated week or two in the course. In this extended approach, the entire course is taught through the constructivist $5 \mathrm{E}$ learning cycle model of inquiry-based teaching whereby students first explore a core idea or concept (e.g. Nature of Science, scientific inquiry), embark in discussions about their experiences, and then formally introduced to these ideas.

In this article, our intent is to discuss our extended 5E learning cycle model introduction and implementation approach. Previous studies (e.g. Hanuscin \& Lee, 2008) have discussed using the learning cycle as "a venue for sequencing learning experiences to help preservice teachers understand 
and apply this approach" (p. 53), but our approach includes active engagement and immersion of students in the process of learning about science and science education content through the 5E model so that they experience learning through this approach before the approach is formally introduced. We will also discuss the various ways in which literacy integration is incorporated into students' experiences and discuss the importance of such integration through the lens of a literacy educator (third author).

\section{Approach to Introducing 5E}

Social constructivism, which is the basis of our entire instruction in our methods courses, requires multiple experiences to challenge preservice teachers' prior conceptions about teaching and learning and "ample time and activities that facilitate the reconstruction of their ideas and abilities" (Bybee, 2014, p. 10). We begin the course with a few weeks devoted to exploring the significance of science education, the nature of science (NOS), and the process of scientific inquiry. In each of those cases, we begin by allowing students opportunities to engage in a number of exploratory activities intermittent with discussions that help unfold students' prior conceptions before presenting accurate and research-based descriptions of these concepts. In this way, we implicitly introduce them to constructivist-based instruction by reversing the order in which concepts are typically introduced. Rather than beginning with a discussion of the features of NOS or what the process of science entails, the preservice teachers first explore these through hands-on and minds-on activities, allowing them to acknowledge their own prior conceptions and gain an in-depth understanding of these concepts once we discuss them.

We then turn our attention to the question of how science should be taught to most effectively address what has been learned about how students learn (NRC, 1999). The sessions devoted to inquiry-based teaching and, more specifically, the 5E learning cycle begin without mentioning either of them. We simply pose the abovementioned question about the approach to teaching science and inform students that the class will be simulating a learning experience, a condensed version of what may occur in an actual elementary classroom, and encourage them to think through the lens of a student going through the process and reflect on the teacher/student roles as well as the instructional approach. The first simulation is a condensed mini-unit focusing on the concept of electricity. The 5E learning cycle is not yet introduced and the stages are not known to the students. Any reference to the stages in the description that follows is intended for providing clarity for the readers as to how these sessions unfold.

Engage.

The engage stage is a critical stage for contextualizing the learning and espousing students' curiosity and interest. This may be achieved through (a) the use of attention-grabbing teacher demonstrations and discrepant events (Liem, 1987), (b) posing a scenario or problem through the use of stimulating video-clips, news articles, or (c) classroom and school specific problems or scenarios. According to the BSCS model of the 5E, during this stage, it is also important to identify students' prior conceptions and experiences with the concept through various forms of diagnostic assessments including simple observations and questioning. The engage stage should not be lengthy or include any introduction of terminology and explanation of concepts by either the teacher or the text. The main goal is to intrigue the learners, focus their attention, stimulate their thinking, and assess their prior knowledge and experiences before the exploration begins (Bybee et al., 2006).

We simulate the engage stage by turning off the lights and stating the following scenario:

You and your friends are on a camping trip and decide to go out for a walk in the woods. However, you end up straying deep into the woods, far from your campsite. Night has fallen and you have no flashlight to find your way back to the camp in the darkness. However, upon looking through your 
belongings, you are able to gather the following items: one functioning battery (from a broken flashlight), a flashlight bulb, and few pieces of coated copper wire.

Explore Stage: Initial Round.

During the explore stage, students participate in collaborative and investigations and activities which require them to probe, inquire, and question, providing for a common set of experiences to build concepts, knowledge, and skills upon (Bybee et al., 2006). The concepts should be explored in small increments, so it is necessary to plan multiple exploration opportunities for students to be gradually exposed to the concept rather than being introduced to a multi-layered series of information and content. For example, in our simulation, we begin with a brief simple exploration activity, described in the next paragraph, in order to introduce the idea of electric circuits and then follow that with a series of exploratory activities and subsequent discussions (refer to exploration/explanation loop section below) to address other related elements and build their understanding of circuits and electricity.

After engaging the students with the scenario, teams are provided with one piece of wire, a size D battery, and a light bulb and begin to attempt to light the light bulb. They are asked to draw the arrangements that do and do not work in lighting the bulb. We circulate to different teams, observing their interactions and asking questions about their observations and ideas that they may be attempting. They normally begin the task by thinking that they could easily light the bulb, but soon realize that most of the arrangements that they attempt "do not work" and begin to either get slightly frustrated or, alternatively, become determined to find a way to light their light bulbs with some scaffolding as deemed necessary by the instructor.

Explain Stage.

The focus in this stage is to develop explanations based on students' prior knowledge and experiences as well as their collaborative exploratory experiences in the previous stage (Bybee et al., 2006). The teacher's role during this stage is to make reference to and facilitate discussion of students' observations, finding, and ideas from the exploration activity to build upon and formally introduce the related concepts and scientific terms. The key word here is 'related'. It is important not to make this stage lengthy or introduce concepts and terminology not yet explored by the students. The formal introduction of concepts should be through a clear and simple presentation connecting the terminology and content to the preceding explore stage and students' prior experience and knowledge. Research is clear that effective vocabulary instruction integrates new vocabulary words with words from students' prior knowledge (Manyak et al., 2014); strategies such as semantic word maps, concept wheels, and concept of definition can reinforce new word learning in the context of what students already know about the science concept under investigation (Duke \& BennettArmistead, 2003). To enhance students' understanding of the concepts, the introduction of concepts by the teacher should be accompanied with other sources of information including audio-visual resources, connecting with experts through Skype or inviting guest speakers to the classroom, and text-based information through children's literature, science books, and textbooks. Exploring new concepts and key vocabulary in multiple contexts, including multimedia experiences, increases the number of exposures students have to new words, further cementing their word learning (Neuman \& Wright, 2014). Incorporating children's literature and informational text is an important resource for developing content literacy skills, such as oral language, vocabulary, reading comprehension, and writing (Everett \& Moyer, 2009; Worth, Moriarty, \& Winokur, 2004).

In our example, once the teams have found a way to light their light bulbs, we pause for a class discussion. Teams are asked to show and explain one arrangement that did and one that did not result in the lighting of the bulb. We then begin to discuss patterns they noticed about the two types of arrangements and their ideas about what seems to be necessary to light the bulb based on what the 
'successful' arrangements have in common. Students mention commonalities such as the need to use all three items, all parts should be connected, and that the connection of the items 'makes it look like a loop, circle or cycle'. We use these student generated ideas to introduce circuits, at this point, limiting the discussion to the basics and not extending to the types of circuits or other elements not yet explored.

\section{Explore and Explain: Iterative Looping.}

As mentioned earlier, it is important to break up the concepts and explore them in segments or smaller increments so that students are not overwhelmed with content. We begin the next stage by extending our earlier scenario: "Back at the campsite, you find several more bulbs from flashlights with dead batteries $\mathcal{E}$ consider making the area brighter by lighting these bulbs too. Try lighting up 2 or 3 light bulbs using one battery and several wires. Draw all arrangements that do and do not work." While students are working with the material, we walk around and approach different teams to ask questions about students' arrangements and how they are similar or different from the first task. Conversations at this stage typically begin to include references to what we just discussed regarding circuits and students begin to discuss the need to 'make sure everything is touching' or 'check to see if the wire is touching the sides of both bulbs.' Once they light two bulbs, some teams automatically proceed to light more bulbs and others are reminded to attempt to do the same. The excitement builds up as they hear a team successfully light three or more bulbs encouraging other to try different configurations.

This stage is followed by a whole class discussion that begins with the teams' sharing of their arrangements and leading to their observations regarding patterns and commonalities they notice across the arrangements. We use this opportunity to introduce the different types of circuits, series versus parallel, and have students examine an online kid-friendly educational website to further read about these two forms of circuits and become familiar with the type and organization of content that would be suitable for elementary students.

We end the discussion by having students generate questions about what they may be interested in exploring based on their observations up to that point. Teams discuss and share their list of questions and a class list is generated. They typically wonder if the wire or the battery could be replaced with other objects and whether or not that would impact the intensity of the light generated. They also wonder whether the size or the number of the batteries used would impact the intensity of the light produced. We inform them that although these various questions would preferably be explored in an actual classroom, they would have a chance to explore the question about the use of other materials in place of the wire due to our limited time. Therefore, we provide them with a small bag containing paper clip, aluminium foil, small piece of wire mesh, brass clip, golf tee, and a small key. We also provide them with a link to an online circuit simulation that allows them to do the exploration virtually so that they can also become familiar with virtual simulations that are available to classrooms. The discussion that follows focuses on their observations in terms of what items may be used instead of the wires and their explanations for why such items may work. Here we introduce the concept of conductivity and the fact that objects may serve as either conductors or insulators and discuss relevant everyday examples such as not touching an outlet with wet hands or a metal.

Another round of 'exploration/explanation' begins. Each team is provided with a small flashlight and asked to disassemble it, examine its various components, make a sketch of the parts and what function they may serve, and discuss possible similarities and differences between the flashlight and their original circuits. Students often find this exploration to be interesting and begin to dissect the flashlight and attempt to make sense of how it works. It is encouraging to hear them use the terms and ideas they have learned such as making the observation that 'all components of the circuit are in there' or 'the metal is touching the sides acting like a conductor' or 'the spring at the bottom is completing the circuit.' They also begin to wonder about the on and off switch and make observations 
as to what happens when they manipulate it. This exploration is followed by another discussion and sharing of observations. We build on their ideas to discuss the parts of the flashlight and introduce the idea of a 'switch' which breaks or connects a circuit allowing for turning on or off a flashlight.

Elaborate.

Once a few rounds of exploration-explanation stages have occurred and students have developed an understanding of a concept or related concepts, they should be provided an opportunity to apply that understanding in new real-world contexts. During this stage, they continue to work in teams and have the opportunity to express their ideas and receive feedback from classmates and teacher. Two typical issues that arise with teachers implementing this stage is that they either confuse the stage with another exploration stage by including another round of investigative task or they think of this stage as an opportunity to further 'explain' or 'elaborate on' a topic. However, this stage is all about students applying what they have explored and learned about. To end our simulation of this mini unit, we ask students to use common household items to construct a flashlight and provide a simple written description of how it works.

Evaluate.

In the learning cycle model, evaluation should be occurring in various forms (diagnostic, formative, and summative) throughout the learning experience. During our simulation, we assessed students through asking questions, observing their interactions, reading their explanations, evaluating their drawings, and so forth. Students should also be encouraged to be metacognitive and reflect on and assess their own learning.

Formal Introduction of the 5E Learning Cycle.

The simulation, discussed above, itself serves as an 'Explore' stage in learning about the 5E learning cycle. Students have thus far experienced what each stage entailed and have been asked to actively think about their experiences. At this point, we formally introduce the $5 \mathrm{E}$ learning cycle (the Explain stage); however, before we do so, we ask the students to work in their teams to discuss what they noticed about each stage that we went through as a class. To aid them in recalling what was done, we provide them with a descriptive handout that describes what occurred in each stage without naming any of the stages (Appendix A). Each team uses its own notes and the handout to discuss what was noticed about the teacher and student roles in each stage and the overall purpose of each. They are also provided a 'typical' lesson on circuits (Appendix B) to analyze and compare to what they experienced with the simulated lesson.

During class discussion, students often note how the 'typical' one starts with introducing all the concepts and terminology and is followed with step by step instructions for building different types of circuits whereas the simulated lesson introduces the concepts after students have investigated first and does so in multiple phases. They also note that our simulation started with a captivating real-life scenario while the 'typical' one began with the teacher lecture or presentation of the content. At this juncture, we formally present the 5E learning cycle (Figure 1) and discuss each stage with examples from our simulation and recommended guidelines including what should be avoided. 


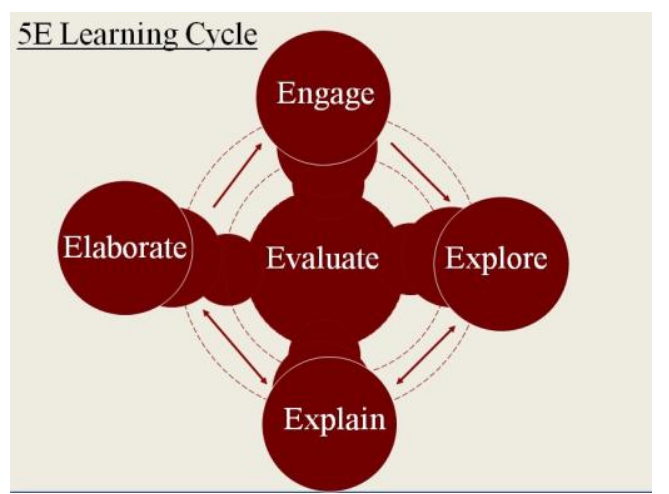

Figure 1. Depiction of the 5E Learning Cycle Based on BSCS Model

Once students have been introduced to the 5E model, we proceed to another mini simulation, this time focusing on density and buoyancy, as an additional opportunity to examine the components of the model. However, since this is more for practice and further clarification of the 5E stages, we only simulate the engage stage and the first brief sinking and floating exploratory activity and discuss how those would be the initial Engage and Explore stages of the mini unit. Students are then provided with a handout containing a chart that includes a description of each stage of the mini unit, in the form of a conceptual storyline (Ramsey, 1993), as it would be carried out in the classroom. We then have teams take some time to discuss the remainder of the stages and try to identify each along with an explanations and justification for each label. We later come back as a class and discuss their labels and explanations which allows us to clarify possible misconceptions or areas of vagueness about the stages. Our experiences have shown that students mainly struggle with the 'elaborate' phase. Sometimes, they are quick to label an early explore stage an 'Elaborate' stage feeling as though the 'Elaborate' stage must somehow fit in after several stages. We use this opportunity to clarify that anytime students are still investigating or attempting to figure out something and there is a concept that needs to be introduced, the stage would be considered an 'Explore' stage.

\section{Application through Planning.}

Once we feel confident that they have a modest grasp of the learning cycle model, students are provided the first opportunity to apply their new understanding. We provide each team with a lesson to analyze and modify into a learning cycle series of stages. Since most available lessons are typically brief one-day lessons, we encourage students to think about extending the lesson into a multi-day lesson that would allow for full development of the concept(s) of focus. Students are also instructed to describe what they would do for the 'Elaborate' stage if their lessons do not extend that far out. This application task allows us an opportunity to evaluate students' understanding of the stages as well as their ability to translate their understanding into the development of an inquiry-based learning cycle experience for students. We observe a number of recurrent patterns in their first attempt at $5 \mathrm{E}$ planning. When planning the 'Engage' stage, students normally include a KWL chart or some type of a diagnostic assessment; however, they typically fail to make this stage engaging or provide any type of context to pique students' curiosity and interest. They normally state that the teacher will inform the students of the topic or ask students 'what they think the lesson will be about'. They normally understand not to include any teacher introduction of concepts or terminology; however, sometimes they include children's literature or video-clips that do just that. We provide feedback that children's literature or video-clips may appear to be 'fun' or 'engaging', but that they would not be appropriate in the engage stage if they introduce terminology and concepts rather than leading to student questions and curiosity.

Students typically do not have major issues with the 'Explore' stage other than making it too teacher directed or providing insufficient description for the students and teacher's role during this stage. For the 'Explain' stage that follows, a few common issues are normally witnessed in student plans. Many 
teams include a class discussion of students' observations and findings, but they fail to include any formal introduction of concepts. Some students include concept introduction; however, they attempt to address more concepts than were explored and view that 'Explain' stage as a culminating chance to cover the topic in its entirety. This means that for more than half of the teams, their learning cycle is limited to only one round of 'Explore' 'Explain' stages and do not include any subsequent looping through these two stages. The culminating course project requires that students write a detailed multi-day science-technology-society (STS) focused lesson plan in the learning cycle format. In evaluating their final projects, it is evident that many preservice teachers improve significantly in their $5 \mathrm{E}$ planning based on the earlier feedback since many of the earlier issues are absent in the final projects.

Discussion forum.

Students participate in a weekly online discussion forum expressing their newly gained understanding of the concepts addressed, making connections to their field experience, and discussing the implications of what they have learned for their future classroom teaching. Students complete a discussion entry after the formal introduction of the $5 \mathrm{E}$ model, reflecting on the tasks, their understanding of the $5 \mathrm{E}$ in relation to what they understood about teaching and learning prior to the course, and the readings. After receiving feedback on their first lessons, they are asked to reflect on the process of writing a learning cycle-oriented lesson and what they gained from the feedback. They normally discuss their interest in teaching using the learning cycle model and being able to relate to it as a student since they found themselves, as one student put it, 'finally understanding circuits since I actually explored it myself!' and interested in 'duplicating that experience for my students.' They reflect on the challenge of writing a lesson that is counterintuitive to what they are used to as students but that the 'in-class simulation helped them see how it all makes more sense when introduced through the 5E model because the students actually explored what the teacher is teaching them.' They find the feedback 'helpful' because they realize areas that 'need further work' and recognize that it is 'easy to fall into the trap of planning as they experienced learning and instruction when they were in school.'

The following week, students are assigned various Science \& Children practitioner articles and asked to analyze the lesson or unit described in the article in terms of alignment with the 5E learning cycle. Since this is after receiving feedback on their first lessons, students' posts are mainly accurate in describing the strengths or shortcomings of the discussed articles. Normally, the main issue they may not allude to is the lack of recursive cycles between the Explore and Explain stages and the brevity of some of the described lessons due to the inclusion of all of the stages, including the 'Elaborate' phase, in a one or two day lesson.

\section{Conclusion}

In preparing pre-service teachers to become effective teachers, we must provide them opportunities to experience first-hand effective, inquiry-based instruction. Rather than explaining what the 5E learning cycle entails and having students memorize what each $\mathrm{E}$ stands for or its order in the cycle, we must ensure that they gain an in-depth understanding of each stage by experiencing the cycle. Furthermore, repeated experiences and discussions are necessary to address possible misconceptions or difficulties in creating learning cycle experiences. The way to break the cycle of ineffective science instruction or the avoidance of science instruction by elementary teachers is to provide them with the experiences that serve as models for them to reflect and build upon. Recurrent cycling through the constructivist 5E learning cycle model of inquiry-based instruction, both implicitly and explicitly, enables our students to gain a deeper appreciation for this type of instruction and witness it in action. 


\section{References}

Kazempour, M. (2013). “The Interrelationship of Science Experiences, Beliefs, Attitudes, and Self-Efficacy: A case study of a pre-Service teacher with positive science attitude and high science teaching self-Efficacy." European Journal of Science and Mathematics Education. 1(3), 106-124.

Kazempour, M. (2014). I Can't Teach Science! A Case Study of an Elementary Pre-Service Teacher's Intersection of Science Experiences, Beliefs, Attitude, and Self-Efficacy. International Journal of Environmental and Science Education. Vol. 9(1), p.77-96.

Kazempour, M., \& Sadler, T. D. (2015). Pre-service teachers' science beliefs, attitudes, and self-efficacy: a multi-case study. Teaching Education, 26(3), 247-271. https://doi.org/10.1080/10476210.2014.996743

Abraham, M. R., \& Renner, J. W. (1986). The sequence of learning cycle activities in high school chemistry. Journal of Research in Science Teaching, 23(2), 121-143.

Appleton, K. (2006). Science pedagogical content knowledge and elementary school teachers. In K. Appleton (Ed.), Elementary science teacher education: International perspectives on contemporary issues and practice. Mahwah, NJ: Association for Science Teachers and Laurence Erlbaum

Beeth, M. E., \& Hewson, P. W. (1999). Learning goals in exemplary science teacher's practice. Science Education, 83(6), 738-760.

Bleicher, R. (2009). Variable relationships among different science learners in elementary science-methods courses. International Journal of Science and Mathematics Education, 7(2), 293-313. doi: 10.1007/s10763-007-9121-8

Bybee, R. W. (1997). Achieving scientific literacy: From purposes to practices. Portsmouth, NH: Heinemann.

Bybee, R. (2014). Guest Editorial: The BSCS 5E Instructional Model: Personal Reflections and Contemporary Implications. Science and Children, 51(8), 10-13.

Bybee, R.W., J.A. Taylor, A. Gardner, P. Van Scotter, J. Carlson Powell, A. Westbrook, and N. Landes. 2006. BSCS 5E instructional model: Origins and effectiveness. A report prepared for the Office of Science Education, National Institutes of Health. Colorado Springs, CO: BSCS.

Duke, N.K., \& Bennett-Armistead, V.S. (2003). Reading and writing informational text in the primary grades. New York: Scholastic.

Everett, S., \& Moyer, R. (2009). Literacy in the learning cycle: Incorporating trade books helps plan inquiry-learning experiences. Science and Children, 47(2), 48-52.

Glasson, G. E., \& Lalik, R. V. (1993). Reinterpreting the learning cycle from a social constructivist perspective: A qualitative study of teachers' beliefs and practices. Journal of Research in Science Teaching, 30(2), 187-207.

Hanuscin, D.L., \& Lee, M.H. (2008). Using the learning cycle as a model for teaching the learning cycle to preservice elementary teachers. Journal of Elementary Science Education, 20, 51-66.

Liem, T. L. (1987). Invitations to Science Inquiry, p.143. Ginn Press, Massachusetts.

Manyak, P.C., Von Gunten, H., Autenrieth, D., Gillis, C., Mastre-O'Farrell, J., Irvine-McDermott, E., Baumann, J., \& Blachowicz, C. L. Z. (2014). Four practical principals for enhancing vocabulary instruction. Reading Teacher, 68(1), 13-23.

Moscovici, H., \& Nelson, T. (1998). Shifting from activitymania to inquiry. Science \& Children, 35(4), 14-17, 40.

McComas, W. F., III. (1992). The nature of exemplary practice in secondary school science laboratory instruction: A case study approach (Doctoral dissertation, University of Iowa, 1991). Dissertation Abstracts International, 52(12), 4284A

National Research Council (NRC). 1999. How people learn: Bridging research and practice. Washington, DC: National Academies Press Neuman, S.B., \& Wright, T.S. (2014). The magic of words: Teaching vocabulary in the early childhood classroom. American Educator, 38(2), 4-13.

Ramsey, J. (1993). Developing conceptual storylines with the learning cycle. Journal of Elementary Science Education, 5(2), 1-20.

Settlage, J. (2000). Understanding the learning cycle: Influences on abilities to embrace the approach by preservice elementary school teachers. Science Education, 84, 43-50

Tosun, T. (2000). The beliefs of pre-service elementary teachers toward science and science teaching. School Science and Mathematics, 100, 374-379.

Worth, K., Moriarty, R., \& Winokur, J. (2004). Capitalizing on literacy connections. Science and Children, 41(5), 35-39. 